\title{
The role of empowering mature and older people's usage of digital media in enhancing intergenerational communication and family relationships in Bahrain
}

\author{
Sama'a Al Hashimi PhD ${ }^{\mathrm{a}, *}$ \\ ${ }^{a}$ Department of Communication, University of Bahrain, Zallaq, Bahrain; Corresponding au- \\ thor: Samaa.alhashimi@gmail.com
}

\begin{abstract}
Background: With the proliferation of mobile applications and social networking sites, it became important to give critical thought to the evolution of social realities and dynamics created by technology. Although technology could be perceived as a threat that may disrupt family cohesion and contribute to intergenerational conflict, there may be certain digital settings, contexts, and uses that can create purposeful social interactions and support the exchange of knowledge among older and younger generations.

Objective: The main objective of this paper is to mount and evaluate an intergenerational digital interaction campaign that encourages the youth in Bahrain to contribute to the digital inclusion of the elderly by teaching senior adults various technical skills. The ICT literature in the Arab world lacks a comprehensive investigation of technology adoption by the elderly, especially in Bahrain. Aiming to understand how advances in technology are challenging the elderly in Bahrain and seeking to empower them in ICT usage, the research endeavors to understand and change the perceived effects of technology within the family context in Bahrain.

Method: This study employs qualitative action-based research and an intergenerational approach that engaged 144 digital media and graphic design students in teaching 144 mature and older people various technological skills in an attempt to suggest and analyse the context in which technology adoption may become beneficial in strengthening familial relationships, and enriching the life quality of older adults in Bahrain. It explores the digital activities that may have a positive impact on social dynamics, by bringing young people and older people together within a digital setting - to communicate, teach, and interact with each other.

Results: The findings suggest that intergenerational learning experiences benefited both groups in learning and skill development and led to a positive change in attitude towards the other generation.

Conclusion: Overall, the study concludes that intergenerational learning experiences foster a positive attitude among the mature and older participants, and provide opportunities for the youth and older people to communicate and build a common ground of understanding. These and the other findings in the research will allow for understanding the context in which technology adoption and the use of digital media may become beneficial in maintaining and strengthening familial relationships, and enriching the life quality of senior adults in Bahrain. Researchers who are interested in this topic may utilize these findings to expand their understanding of how the digital inclusion of the elderly may enhance intergenerational and family relationships, especially in the Arab world.
\end{abstract}

Keywords: Older people, technology, digital media, digital divide, technology adoption, digital literacy

\section{INTRODUCTION}

The mature adults (aged 55-64) and older adults (aged 65+) in Bahrain have conventionally been an excluded group in the utilisation of technology (Al-Ammary, 2010). Even though their use of technology is growing, there is still a significant agebased digital divide (Al-Ammary, 2010). The digital divide is defined as the gap between individuals at different socio-economic levels in terms of their opportunities to access and use information and communication technology (Ye \& Yang 2020).
While technology is becoming globally more pervasive, an age-related digital divide and underutilisation of technology by older adults remains observable (Niehaves and Plattfaut 2013). For instance, mature and older people are significantly less likely to use the technology than the average population (Niehaves and Plattfaut 2013).

Many studies further investigated the challenges, factors, and obstacles that prevent many older 
people from using technology to enhance their quality of life (ex: Niehaves and Plattfaut 2013). These obstacles include physical and health problems that limit their Information and Communication Technology (ICT) usage, lack of a computer with Internet access, and lack of interest in technology (Czaja and Lee 2007). Moreover, there is a lack of recognition and awareness of the specific design requirements of older people (Alsswey and Al-Samarraie 2018) as well as insufficiency in their involvement in the decision-making process and usability of technological tools and applications (Milligan and Passey 2011).

Despite the significance of this phenomenon, the ICT literature in the Arab world lacks a comprehensive investigation of technology adoption by the older people (Khawaji 2017), especially in Bahrain. A study by Khawaji (2017) examined the use of smartphones and other new technologies among seniors in Saudi Arabia, while another study by Alolyan (2015) explored the perceived impact of the internet on family and social relations also in Saudi Arabia. There are several studies published in other country contexts on the impact of digital media on intergenerational relationships (eg. Alolyan 2015, Lindsay, Smith and Bellaby 2007, Lanigan, Bold, and Chenoweth 2009), however hardly any studies on this topic exist in Bahrain. Moreover, these studies are mostly based on the exploration of such initiatives in western countries (Khawaji 2017), and do not address whether or not the impact of intergeneration digital inclusion approaches on social dynamics is different in a non-western family-oriented country such as Bahrain. The rise of social media platforms and other digital media has been considered a double-edged sword by many people in and out of Bahrain (Alsridi 2019, Condotta 2018, Arora, S. 2015). Some researchers believe that these technologies have led to negative changes in social relations (Siddiqui, $\mathrm{S}$. and Singh 2016, Akram and Kumar 2017). This has also been echoed by some researchers in the region (eg. Alolyan 2015, p.35) who suggested that the internet has led to less "intra-family interaction" because people started substituting their online interaction for real-life interaction, and many of them may be "physically present at a family or social event but mentally engaged with the internet and social networks". For this reason, the research mainly aims to achieve the following objectives:

- To explore the consequences and dimensions of employing technology to enhance intergenerational relationships

- To change the prevailing negative attitudes towards technology

- To increase the levels of digital literacy among older people in Bahrain
- To highlight the mechanisms, patterns of usage and interaction, and social situations that best enable older people to benefit from digital media

The paper proposes empirical-based best practice guidelines for incorporating technology adoption in an intergenerational approach that may encourage the digital and social inclusion of the older people, and bridge the digital divide in Bahrain. These guidelines are recommended in the discussion section, which explains the recommendations and strategies that should be sought to utilise, exchange, and build on the intergenerational approach for the benefit of both generations.

Some researchers suggested that social media and technology have negatively influenced social relationships and intergenerational interactions (Moawad and Ebrahem 2016; Subramanian 2017; Lanigan, Bold, and Chenoweth 2009). To overcome this problem, this research aims to employ an intergenerational approach in an attempt to digitally empower the older people in Bahrain, while allowing technology to play a significant role in strengthening rather than weakening social relationships. In order to achieve this objective, the research involves a literature review that benchmarks worldwide experiences and initiatives of digital literacy training for people aged over 55 and then builds on their guidelines for the teaching of digital literacy to mature and older people.

Our main research question is: 'How intergenerational digital interaction may be implemented to bridge the digital divide and to provide opportunities for the youth and the older people to communicate and build a common ground of understanding?'

To answer the aforementioned research question, this paper consists of five sections. The first section presents a brief introduction to the action research and discusses the underlying motives. It presents the objectives that are to be achieved and the research problems and questions that are to be examined and outlines the theoretical framework of the research as a whole. The second section notes the research literature that has been globally done concerning the older people's usage of technology. It also contains a literature review of the state-of-the-art in the various countries with intergenerational learning strategies and initiatives related to digital literacy for older people. The literature review is designed to qualitatively examine multiple international cases and initiatives that employ the intergenerational approach. The third section explains the methodological approach of this study. The fourth section investigates how the older people in Bahrain feel about emerging technologies and 
how they integrate these technologies into their lives and presents the results of our evaluation of the effectiveness of intergenerational digital interaction in empowering the older people's adoption of technology and usage of digital media. Finally, the discussion section followed by the concluding section draws together the key findings and reflections of the study before proposing new research directions and desiderata.

\section{Literature ReVIEW: TheORETICAL PERSPECTIVES ON THE IMPACT OF THE INTERGENERATIONAL APPROACH TO DIGITAL EMPOWERMENT ON SOCIETAL AND FAMILY RELATIONSHIPS}

Although the technology was considered by many as a reinforcer of the intergenerational gap especially between family members, some researchers found that digital media is contributing to the diminishment of this gap (Livingstone \& Haddon 2009 and Bolin \& Skogerbø 2013). Digital media is defined as products and services that include digital platforms, content, and services that can be accessed through digital devices (World Economic Forum 2016).

The intergenerational approach, which involves youth-adult collaboration to digitally empower older adults, is not new. Many years of work and research involving the implementation of this approach have acknowledged the responsibility young people have toward improving older people's lives. According to a study by the International Center for Research on Women (2003), evidence shows that the intergenerational (IG) approach helps young people and adults in forming healthy and strong relationships in which they collaborate with and learn from each other.

Intergenerational learning is defined as the "systematic transfer of knowledge, skills, competencies, norms, and values between generations" (Hoff, 2007, p. 126). A number of researchers emphasised the role of intergenerational learning in social contexts (Patrício and Osório 2016), stating its importance in "strengthening intergenerational relations, reducing barriers, and breaking negative stereotypes between generations (Ropes, 2011; Spannring, 2008)" (Patrício and Osório 2016, p.85).

This literature review is therefore conducted to document theories, experiences, attitudes, and findings regarding the impact of youth-adult collaborations and interactions on promoting technology use among older adults, and to examine the extent to which the intergenerational approach is being employed to support the theory that technology does not always negatively influence the ties between older and younger people and that digital interaction may be implemented effectively to bridge the digital divide and to benefit both older and younger generations and contribute to social cohesion. The relationship between technology and the way interpersonal relationships are experienced has been explored by Madianou and Miller (2013) who developed the theory of polymedia. This theory emphasizes the role of emerging and proliferating communication technologies in forming a new set of social relations. This is also emphasized in the book titled 'Aging and Digital Technology' by Neves and Vetere (Eds.) who believe that emerging technologies can lead to positive outcomes and "social connectedness" (Neves and Vetere 2019). The authors listed three dimensions of social connectedness; personal relationships, community connections, and societal engagement. The book considers these dimensions while it attempts to present theoretical and methodological frameworks that can inform the design, implementation, evaluation, of emerging technologies for older people.

The utilization of technology to promote social interaction and connectedness between seniors and youth was also explored in Austria. The project 'TiK-Technology in brief-Tablet for everyone' implemented an intergenerational learning approach by encouraging young trainers (aged 16 to 30$)$ to offer digital literacy courses to over 2,000 older citizens from economically disadvantaged backgrounds and with a low level of education (UNECE, 2019). In France, the 'digital pass' project provides free ICT training to older employees. While the 'digital bus' project offers free training lessons on "sending emails, filling out tax forms, etc. to seniors." (UNECE, 2019).

At Michigan Technological University, the Breaking Digital Barriers group has run a program called BASIC (Building Adult Skills in Computing) that pairs students with older participants who require help with technology (Atkinson, Barnes, Albee, Anttila, Haataja, Nanavati, Steelman, and Wallace 2016). The program allowed the researchers to identify a number of barriers that older people face while interacting with technology. In addition to physical, motor, and perceptual impairments, the researchers suggest that motivation and awareness are among the factors that hinder older adults' interaction with technology. Additional barriers to digital literacy include anxiety, fear of fraud and identity theft, and lack of awareness that many platforms are accessible and consistent across devices. Some of the effective techniques that were employed by the tutors as part of the program include: inviting learners to state their specific needs and goals to then tailor one-on-one tutoring sessions for them accordingly; vocalizing the actions while they are performing them and modeling their behaviours and emotional reactions when 
they are unable to act in order to demonstrate to the participants the unnecessity of feeling anxious and to show them that even experts may need assistance sometimes (Atkinson et al. 2016). This experience has shown that attitudes and motivations within cultural and social contexts can negatively or positively influence the adoption of digital technology among older people and that such an intergenerational approach can assist them in increasing their digital literacy (Atkinson et al. 2016). Further research is needed to investigate the effect of such an experience on older people's interests, needs, preferences, and patterns of using ICT.

The results of another study by Patrício and Osório (2016) show that the intergenerational approach enhances social cohesion and "contributes to the digital literacy of adults and seniors and fosters lifelong learning, active aging, and understanding and solidarity among generations" (p.83). The researchers in this study stated the importance of developing opportunities for collaboration and learning between generations. Their intergenerational multiple case studies led them to identify a number of difficulties faced by older people including: "lack of confidence, technophobia, problems with technology and accessibility [...] difficulty in handling the mouse or keyboard [...] lack of time and support, technological demystification, and cognitive skills (lack of concentration, attention, and memory and mental tiredness)" (Patrício and Osório 2016, p. 92). Nevertheless, their analysis revealed that the encouragement of the younger generation contributed significantly to the dissipation of some of these difficulties and promoted older people's interest in new technologies as well as strengthened family ties (Patrício and Osório 2016).

Thus, the previous two studies support the theory that the barriers to digital technology adoption include social barriers, which can be effectively diminished through the implementation of the intergenerational learning approach.

Furthermore, a study by Atkinson et al. (2016) also seems to support the above-mentioned assumption that the intergenerational approach may help in "demotivating feelings of anxiety and confusion". The study identified additional social barriers and obstacles that are "[...] beyond the more clearly understood physical and cognitive barriers traditionally associated with accessibility [...] The barriers to access are substantial, spanning from traditionally accepted factors like physical, motor, and perceptual impairments [9] to less measurable factors such as motivation, awareness, and perceived benefit" (p.239). In addition to the aforementioned barriers, Digital McKinsey report shows that "the offline popula- tion faces the following barriers: incentives and lack of compelling reasons to go online, low incomes and affordability, user capability, and barriers in infrastructure." (Elmasry, Benni, Patel, and aus dem Moore 2016, p.52)

The rest of this paper aims to further assess these barriers and investigate if and how an intergenerational approach to digital inclusion can improve social dynamics, and its effectiveness in minimizing the social barriers.

\section{The mature and older citizen's growing en- gagement and widening adoption of digital technologies}

Alongside the rapid growth of the older population, their adoption of technology has been increasing throughout the years (Alsswey and Al-Samarraie 2018). To further accelerate this progress, it is important to investigate and understand the difficulties that the mature citizens and the older people face during their interaction with new technologies, and the obstacles that prevent some of them from adopting these technologies. It is equally important to explore the technology adoption advantages that they consider to have a positive influence on their life quality. Research shows that older citizens are interested in digital literacy, citing various advantages (Kolodinsky, Cranwell and Rowe 2002; Alsswey and Al-Samarraie 2018; Neves and Vetere 2019). These advantages include maintaining social interaction with family and friends, learning new skills, researching personal interests, staying up-to-date with current events, managing financials, getting health-related assistance (Kolodinsky, Cranwell, and Rowe 2002). Norris believes that technology can improve the quality of life of the older people stating that "The Internet seems well suited to the needs of the older people, as a fairly sedentary population with considerable leisure time, especially for social networking, hobbies, and services as the home delivery of groceries" (Norris 2001, 84 as cited in Neves and Amaro 2012). This positive influence on their life quality is also emphasised by Alsswey and Al-Samarraie (2018).

Despite these benefits and the increasing technology adoption by older users, research indicates that "many find themselves without sufficient user skills" (Hill, Betts and Gardner 2015 as cited in Rønning and Sølvberg 2017, p.56);

Without appropriate skills, they may risk being excluded from participating fully in society [...] Moreover, the digital divide is likely to widen as more information and public and private services migrate to the virtual world. Friemel (2016) describes this as the 'second-level' digital divide. (Rønning and Sølvberg 2017, p.56). 
A number of researchers attempted to find explanations and reasons for older people's use and non-use of technology. Some of them suggested that the factors that determine their engagement with technology include both demographic and individual factors such as level of education, income, employment, class, gender, disability, racial and ethnic background, attitudes, interest or motivation and self-efficacy (Rønning and Sølvberg 2017). Other factors include income, education, geographical location, disabilities, and the difficulty of new technology (Roupa, Nikas, Gerasimou, Zafeiri, Giasyrani, Kazitori and Sotiropoulou 2010).

While some studies have shown that the elderly are willing to use technology and can use it with proficiency (Czaja and Lee 2007), other studies indicated that "Computer and Internet usage are negatively correlated with age" (Antonio 2018; Norris 2001; Rice and Katz 2003). Neves and Amaro (2012) suggested that job performance seems to decrease around the age of fifty, and they indicated that the decrease in productivity in older populations is more noticeable in tasks involving problem solving, learning, and speed. They stated that the older people are slower in learning new skills and performing some cognitive tasks. Their ability to concentrate, remember, and solve new problems based on previously acquired knowledge, which is referred to as "General Fluid Intelligence" (Jaeggi et al., 2008 as cited in Neves and Amaro 2012), declines with age and significantly impacts their technologyadoption capabilities. Nevertheless, Czaja \& Lee (2007 cited in Neves and Amaro 2012) suggest that general fluid intelligence can be improved with training and that crystallized intelligence, which is important for ITC usage and training.

While investigating levels of use of specific technologies amongst older people, McCann and Bryson (2015, p.50) suggest that "any digital divide is more likely to be associated with specific technologies or certain practices, rather than with all technologies and all internet uses and practices". Correspondingly, Neves and Amaro (2012) suggested that the type of training and the design of the system affect the older people's learning and usage of technology and therefore advocates involving the older people in the design of technological products and providing them with effective training in order to improve their engagement. In an attempt to empower the older people usage experience of technology and provide design solutions, Umar and Al-Samarraie (2018) suggested examining certain cultural aspects in the user interface design, and they developed a set of guidelines for mobile interface design specifically for Arabic users. Furthermore, training programs must be structured and specifically designed for their level of education, capabilities, and knowledge. Some programs involve young adults teaching computer skills to older adults. These programs have revealed that they have a positive impact on seniors and youth. This impact is exemplified through the mutual learning, enhanced attitude and interaction between the two generations;

Seniors who participate in these programs show a positive change in attitudes towards computers and the Internet, and a gain in confidence in their own proficiency with technology. Youth who participate in these programs as the 'teacher' show improved leadership skills and gain a sense of personal-worth based on their contributions to society. Research shows that intergenerational activity offers heightened learning for both groups, increases self-confidence, increases cross-generational comfort levels, eliminating stereotypes that each generation may hold for the other (Bullock \& Osborne, 1999; Chen, 1997; Pinquart, Wenzel, \& Sorensen, 2000; Shipman, 1999). (Kolodinsky, Cranwell, and Rowe 2002).

Because these programs involved young adults teaching computer skills to older people who were not necessarily family members, the positive consequences of their successful intergenerational approach were not tested - and perhaps augmented - within the social system of families. The implementation of such an approach among family members, which is part of this research, may help enhance family communication and provide new kinds of opportunities for young family members to communicate with the mature and older members.

In line with the above-mentioned positive consequences, researchers found that "the Internet can help improve family communication and provide opportunities for grandparents and grandchildren as well as parents and adult children to collaborate" (Mesch 2006; Orleans and Laney 2000 as cited in Lindsay, Smith and Bellaby 2007, p.4). Research findings indicated that technology has several positive consequences on family ties and built new common interests among children, grandchildren, siblings and spouses (Lindsay, Smith and Bellaby 2007). The older people in families with closer family ties had a greater tendency for technology adoption as grandparents were inspired to learn by their grandchildren (Lindsay, Smith and Bellaby 2007). They were more motivated to learn computer skills and use technological devices because their grandchildren were using them (Lindsay, Smith and Bellaby 2007).

Thus, the above-mentioned intergenerational approach, for instance, may possibly minimise 
the digital as well as the social gap, especially if conducted within a family theoretical framework and directed towards studying and understanding the negative and positive perceptions of technology impact within family contexts. Therefore, this research aims to measure the perceived changes in the skills and attitudes of both older and younger family members while working with each other on overcoming the challenges the mature and older adults face during technology adoption. Consequently, it seeks to set out a number of ways in which the young generation can develop new approaches to accelerate digitisation among people over the age of 55 in an attempt to highlight the approaches and social situations that best enable this group to benefit from technology.

\section{Literature review of previous research and inter- generational initiatives to foster digital literacy}

Many studies suggested that social media and technology have negatively influenced social relationships in a variety of ways (Moawad and Ebrahem 2016; Subramanian 2017; Lanigan, Bold, and Chenoweth 2009). For this reason, this research aims to employ an intergenerational approach to let technology contribute to strengthening rather than weakening these relationships. According to the 'Grandparents and Grandchildren Project' report (2013), intergenerational learning involves activities through which young people assist older people in learning skills for managing themselves and their necessities. The report states that with the prevalence of technology the roles between the older and the younger have changed. Correspondingly, Neves and Amaro $(2012$, p.10) suggest that grandchildren play a major role in encouraging grandparents to adopt new technologies by showing them how to use various devices. During the last few years, more systematic intergenerational initiatives and programs have arisen. There are many projects initiated in various countries, which have aimed to enhance ICT skills of older people. In this section, we present some of these projects and initiatives in order to get inspiration and gain experience from their challenges and recommendations, before applying a similar approach in Bahrain.

A lot has been achieved in Europe to minimise the digital divide between the generations. Countries like Denmark, Iceland, Sweden, organised special ICT training projects for older people during the past decade. The European Cohesion Funds (ESF) supported many initiatives to encourage e-inclusion in an attempt to allow every citizen to have the opportunity to benefit from information society (Grandparents and Grandchildren Project 2013). One of these initiatives is the 'Grandparents and Grandchildren' project (2013) which reflects a successful experience of digital literacy training addressed to older people. The project engaged people aged over 55 with secondary school students who volunteered to be their 'digital educators' (Grandparents and Grandchildren Project 2013). The students reported that they enjoyed the communication with the older participants and felt that the environment was "friendly and family-like". They also said that the older women felt as though their grandchildren were teaching them. The project report stated that the women felt relaxed because the environment was "informal, social and fun", and suggested that formal teaching methods should be avoided in order for the participants to feel relaxed (Grandparents and Grandchildren Project 2013, p.14).

Another significant project, which involved reciprocal intergenerational learning activity is LIST (2013). This project aimed at increasing older women's ICT competences and digital literacy, and to support their ability to access e-services. It engaged high school students with older women in digital training sessions in which they taught them various skills including how to use Facebook. Based on their experience from this project, the researchers wrote a number of important recommendations. They also suggested that such intergenerational programs must be implemented in collaboration with high schools in order to succeed. Furthermore, to ensure the success of the project, computer jargon must be avoided; "One of the most off-putting aspects for older people is the terminology; 'Computer-speak' is not simply confusing but can act as a significant barrier both to ICT use and to communication about it" (LIST 2013, p.49). The researchers also emphasise the importance of considering older people's motivation for digital participation, and to address them through teaching them what they request to learn. They also stress the importance of considering the limitations of older people; "Older people vary enormously in their physical and mental abilities and the trainers need to adapt their style of interaction to the capability of the person they are talking with." (LIST 2013, p.49)

Another initiative, which aimed at supporting older people's social and digital inclusion through an intergenerational approach is The Digital Age Project. The project engaged ten older learners with ten teenage tutors to teach them how to get online and benefit from online recourses to improve their lives. The teenage tutors were guided by an online toolkit resource specially created for this project (available for download at www.digital-age.org.uk). They taught the older people various skills including the use of email, skype, online-shopping and booking websites, social media, YouTube, and Pinterest. The project aimed to enhance older people's digital 


\section{Empowering mature and older people's usage of digital media}
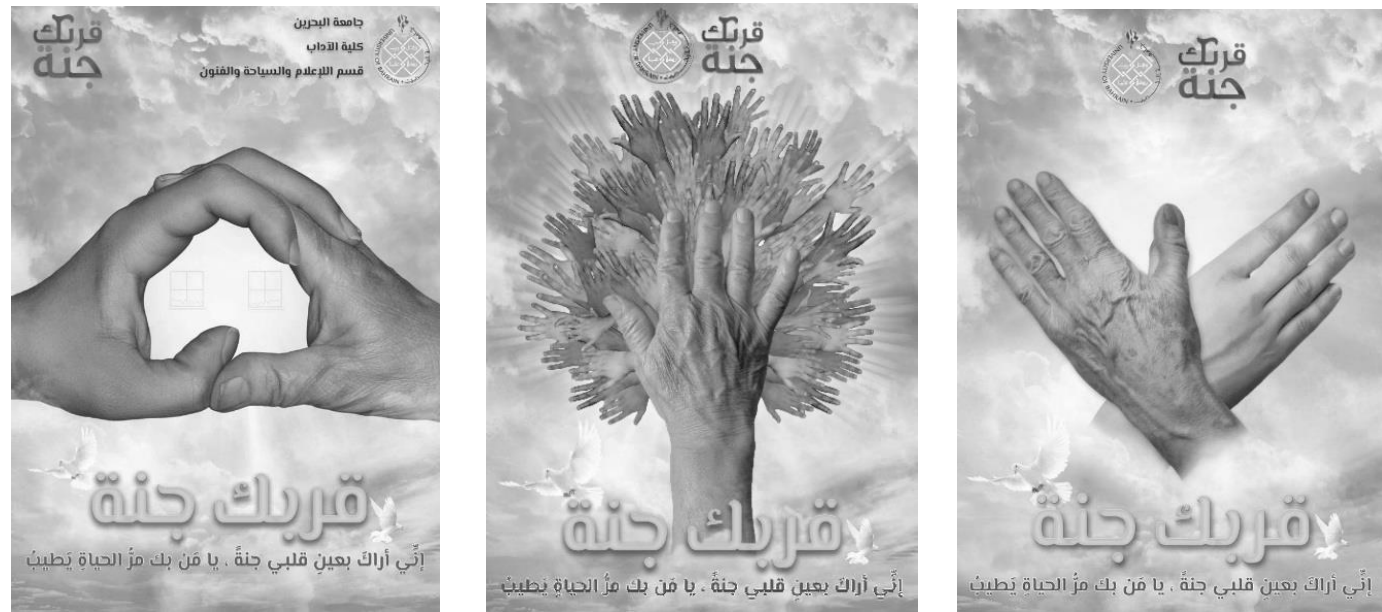

Figure 1. The social awareness posters that were designed as part of the Digital Gratitude campaign.

literacy and overcome social isolation by connecting older people with the younger generation. The younger tutors had the opportunity to acquire valuable knowledge and life experiences from an older generation and play a significant role in society (http://linkinggenerationsni.com).

The literature review in this section demonstrates that the call for increased intergenerational interaction has come from many countries during the past few years. The call is conveyed through a broad range of studies and intergenerational program initiatives, which address the increased sense of social exclusion and isolation experienced by many older adults. This suggests that there is a growing recognition that these endeavours can facilitate effective intergenerational interaction and communication, and thereafter contribute to strengthening the relationships within the society in addition to improving the life quality of older people.

However, conscious efforts to encourage intergenerational digital interaction have not yet been deployed in the Middle East or Bahrain. In order to keep up with all the above-mentioned worldwide initiatives, and to reflect on our own cultural experience of intergenerational learning in Bahrain, we implemented an intergenerational action-research project, which will be discussed in the following section.

\section{Methods}

Aiming to understand how advances in technology are challenging the older people in Bahrain and seeking to empower them in ICT usage, we attempted to explore their patterns of usage and perceptions. Therefore, we examined the effectiveness of the media campaign as a qualitative action-based approach for framing youth support for wider adoption of technology by the old- er people, and for understanding and changing the perceived effects of technology within the family context in Bahrain. This study suggested that the digital inclusion of older people may enhance intergenerational and family relationships. It involved mounting an intergenerational digital interaction campaign that encouraged the youth in Bahrain to contribute to the digital inclusion of the older people by teaching them various technical skills. It hence evaluated how this intergenerational digital learning experience may foster a positive attitude between both generations, and investigated how digital media and technology - in general - may be used as a medium that provides opportunities for the youth and the older people to communicate, exchange knowledge, and build a common ground of understanding.

Attempting to extend the breadth and range of inquiry, the study was based on a mixed-methods approach, combining quantitative and qualitative techniques. Qualitative data analysis preceded quantitative data analysis because the aim was first to qualitatively explore the dimensions of employing technology to enhance intergenerational relationships and then to follow up on this exploration with quantitative data that are amenable to applying the findings to mature and older people in Bahrain in general. The research involved a two-phase sequential study; first, we conducted an action-research project that engaged 144 digital media and graphic design students in teaching 144 mature adults (aged 55 - 64) and older people (65 and above) various Information and Communication Technology (ICT) skills in an attempt to improve their digital literacy. Second, we surveyed the 144 students to explore the implications of the intergenerational approach and to explore the challenges and benefits of digital media usage by older people. Quantitative survey results were analysed using 


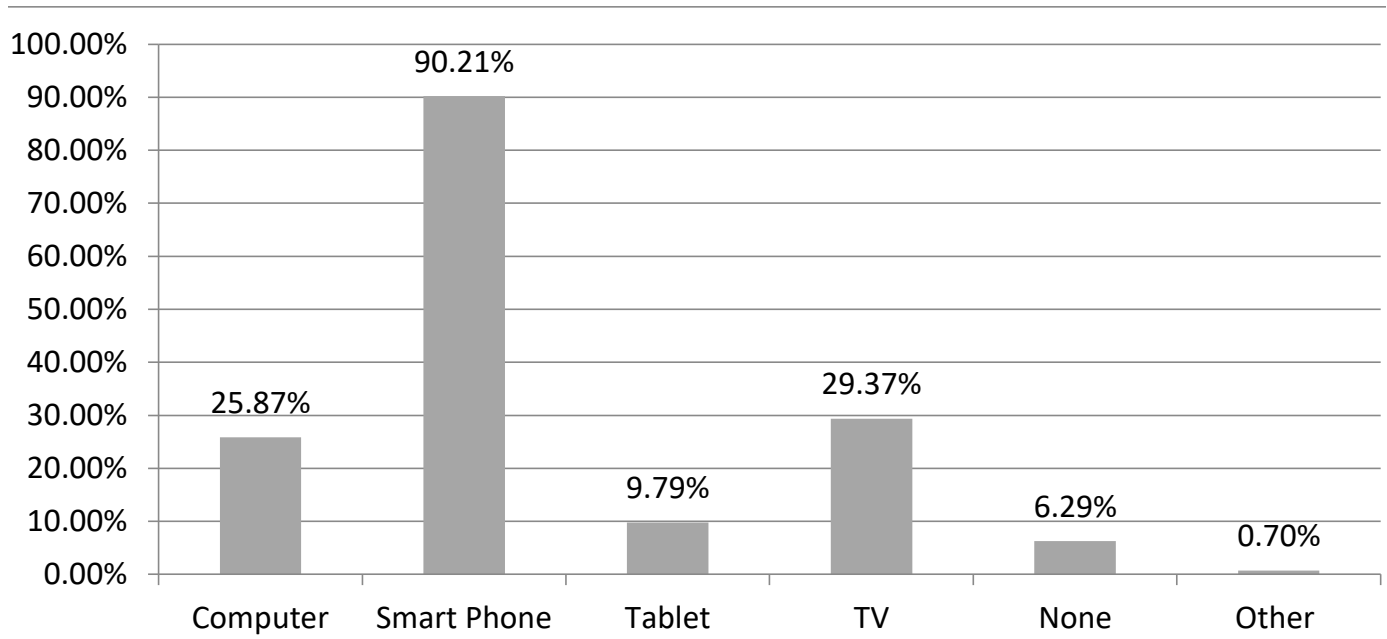

Figure 2. The kinds of electronic devices owned by the older participants.

Excel and SurveyMonkey.

The first stage of the project included organising a campaign called 'Qirbak Jannah' (i.e. Your Closeness is Paradise); a media outreach campaign aimed at promoting intergenerational communication and interaction by encouraging young people in Bahrain to contribute to the digital inclusion of older people through teaching them the various technical skills that may enhance their digital literacy. The campaign involved a number of endeavours for convincing young people that ways and means of charity or gratitude for older people can take various innovative forms that keep up with the requirements and trends of the present age, and may be in the form of digital charity or gratitude. The campaign was organised by 15 students who were enrolled in a course titled 'Computer Graphics' and another course titled 'Social Marketing' under the joint supervision of Dr. Layla Al Saqer and Dr. Sama'a Al Hashimi at the University of Bahrain. The students from both courses collaboratively worked on the campaign as part of their final project, which involved the following:

- Visiting Muharraq Center for Social Welfare and Abdullah bin Yusuf Fakhro Social Center, and teaching older people various artistic, technical, and manual skills as well as reading books and newspapers for them.

- Posting social awareness posters (Figure 1) through social media platforms to encourage young people to pay attention to and communicate with older people.

- Media coverage of the campaign through the media, including television, radio and press interviews.

- Launching contests and prizes that encourage young people to start any initiatives or design any projects that can enhance communication with older people and bridge the gap between generations.

- Organising an exhibition in the University of Bahrain in May 2017 to target university students and encourage them to participate in the campaign and contribute in the implementation of its objectives.

- Organising awareness and counselling lectures about older people by a number of specialists and psychologists from Al Muharraq Centre.

The second stage of the initiative involved an action-research project that engaged 144 graphic design and digital media students in teaching 144 mature and older adults' various ICT skills in an attempt to improve their digital literacy. The students were enrolled in an undergraduate art and design program at the University of Bahrain and were encouraged through an e-mail invitation to volunteer and undertake the task with any family member who is more than 55 years old. This age group was targeted due to evidence that the decrease in using computers and technology appears to be particularly sharp among citizens aged over 54 (Grandparents and Grandchildren Project 2013).

An online survey consisting of closed and openended questions was developed for the students to administer on behalf of the older adults in order to evaluate their overall experience. The questions addressed the older adults' learning experience and the difficulties they encountered in an attempt to measure perceived changes in their skills and patterns of interaction, and to explore the factors that affect their ICT usage. Some questions also addressed students' experience and satisfaction with the intergenerational action-research project in an attempt to analyse changes in their attitudes towards working with an older generation. Qualitative analysis, which involved the discourse analysis approach was conducted for open-ended questions, and de- 
Table 1. Demographic data of the older participants $(N=144)$.

\begin{tabular}{|c|c|c|}
\hline $\begin{array}{l}\text { Gender } \\
\text { Male } \\
\text { Female }\end{array}$ & $\begin{array}{l}\text { No. } \\
75 \\
69\end{array}$ & $\begin{array}{c}\text { Percentage } \\
52 \% \\
48 \%\end{array}$ \\
\hline Age & \multicolumn{2}{|c|}{ Value } \\
\hline Sample size & \multicolumn{2}{|r|}{144} \\
\hline Mean age & \multicolumn{2}{|r|}{59.7} \\
\hline Standard deviation & \multicolumn{2}{|r|}{5.4} \\
\hline Min age & \multicolumn{2}{|r|}{55} \\
\hline Max age & \multicolumn{2}{|r|}{80} \\
\hline Social status & Value & Percentage \\
\hline Married & 117 & $81 \%$ \\
\hline Single & 7 & $5 \%$ \\
\hline Widowed & 14 & $10 \%$ \\
\hline Divorced & 6 & $4 \%$ \\
\hline Total & 144 & $100 \%$ \\
\hline Family status - children & Value & Percentage \\
\hline Parents & 116 & $80.8 \%$ \\
\hline No children & 28 & $19.2 \%$ \\
\hline Total & 144 & $100 \%$ \\
\hline Family status - grandchildren & Value & Percentage \\
\hline Have grandchildren & 88 & $61 \%$ \\
\hline No grandchildren & 56 & $39 \%$ \\
\hline Total & 144 & $100 \%$ \\
\hline Language skills & Value & Percentage \\
\hline Understand and speak English & 75 & $52 \%$ \\
\hline Don't understand and speak English & 69 & $48 \%$ \\
\hline Total & 144 & $100 \%$ \\
\hline Education & Value & Percentage \\
\hline Did not graduate from school & 62 & $43 \%$ \\
\hline Less than a bachelor degree & 62 & $43 \%$ \\
\hline Bachelor degree & 16 & $11 \%$ \\
\hline Master degree & 1 & $1 \%$ \\
\hline $\mathrm{PhD}$ & 3 & $2 \%$ \\
\hline Total & 144 & $100 \%$ \\
\hline Work status & Value & Percentage \\
\hline Never had a job* (most are housewives) & 53 & $37 \%$ \\
\hline Working & 22 & $15 \%$ \\
\hline Retired and still working & 23 & $16 \%$ \\
\hline Retired and stopped working & 46 & $32 \%$ \\
\hline Total & 144 & $100 \%$ \\
\hline Possession of electronic devices & Value & Percentage \\
\hline Mobile phone & 130 & $90 \%$ \\
\hline Other devices & 14 & $10 \%$ \\
\hline Total & 144 & $100 \%$ \\
\hline
\end{tabular}

scriptive quantitative statistical analysis was performed for closed-ended questions. Discourse analysis is the study of social life through the analysis and investigation of meaning whether through face-to-face conversation, verbal and non-verbal interaction, or other ways of communication (Shaw \& Bailey 2009). The demographic analysis of our survey sample of mature and older participants $(\mathrm{N}=144)$, has shown that $48 \%$ were female, and $52 \%$ were male. Their mean age was 59.7(SD = 5.4), and participants' ages ranged from 55 to 80 years. On the other hand, the students' $(\mathrm{N}=144)$ ages ranged from 18 to 29 years, and their mean age was 21.9 (SD = 2.3). Most of the survey participants were married $(81 \%)$. The remaining participants were single (5\%), widowed (10\%), or divorced (4\%); $80.8 \%$ are parents and $61 \%$ have grandchildren. More than half (52\%) understand and speak English. In terms of their education, only $11 \%$ had a bachelor's degree, $43 \%$ had less than a bachelor's degree, $43 \%$ did not graduate from school, $1 \%$ had a master degree, and $2 \%$ had a PhD. In terms of occupation, $32 \%$ of the participants were retired and stopped working, 16\% were retired, but are still working, 15\% were still working, and the rest $(37 \%)$ never had a job (most of them were housewives). In terms of their possession of electronic devices, the majority $(90 \%)$ own mobile phones, while the possession of other devices remains less comparatively (Figure 2). The majority $(58 \%)$ of the students performed the task with their parents, 15\% with their grandparents, 7\% with their aunts, $8 \%$ with their uncles, and $6 \%$ with other members or friends of the family, or neighbours. Table 1 summarizes the older and mature participants' demographics. The findings will be discussed throughout the next section.

\section{Results: BRIDGING THE DIGITAL DIVIDE BY IMPLE- MENTING AN INTERGENERATIONAL APPROACH TO REACH OUT TO THE MATURE ADULTS AND OLDER PEO- PLE IN BAHRAIN}

In 2017, we started The Digital Gratitude Project, which is an initiative for the digital inclusion of older people in a number of ways that promote intergenerational relations and the consolidation of family relations, in order to achieve the following objectives:

(1) Promoting inter-generational communication and interaction by encouraging young people in Bahrain to contribute to the digital integration of older people by teaching them the various technical skills that contribute to improving their living conditions and quality of life, and to stimulate their social role and help them to carry out their daily tasks;

(2) Bridging or reducing the social and digital divide between generations;

(3) Creating opportunities to exchange knowledge and experience and recycle the accumulated knowledge, experience and accumulated experience of older citizens so that the youth can re-establish, develop, disseminate and re-establish them in the Bahraini society in proportion to the age of technology.

(4) Changing common and futile uses of social media and perceived negative effects of technology within the family context in Bahrain.

The students (tutors) indicated that they taught the older participants various skills, including online shopping, accessing e-government services and news apps and websites, installing mobile applications, capturing and editing photos and videos, sending e-mails, using Microsoft Word and Google Maps. The majority of students taught the participants how to use social media platforms such as Instagram, Snapchat, Twitter, WhatsApp, Pinterest, and YouTube. The time each student spent with a participant ranged between 5-30 minutes approximately; the majority of students spent 10 minutes (32\%) to 15 minutes (19\%) per session, and the average time that was spent by 


\section{Empowering mature and older people's usage of digital media}

all the participants was 13 minutes. According to the students, the following were some of the tasks that the participants requested to learn: "making online transactions, such as paying bills, which would otherwise require going personally to government entities"; "searching for online newspapers"; "making travel reservations"; "photo editing and manipulation"; "paying bills through e-government online services"; "sending voice messages through WhatsApp"; "sending emails"; "Tweeting"; "using Snapchat in order to watch her daughters' snaps"; "making video-calls". The majority of the tasks that the participants wanted to learn included social networking activities, followed by requests to read online news, capturing photos, and making online transactions, respectively. These preferences or requirements seemed to be influenced by gender and associated sociocultural aspects. Some female participants, for instance, expressed their interest in using YouTube in order to watch cooking tutorials, while many of the male participants wanted to learn how to perform online transactions and bill-payments. Most of the participants who wanted to learn how to use WhatsApp, specifically wanted to know how to send voice messages in order to be able to communicate with their children and other family members and friends without having to type or read small letters. Others who were interested in learning how to capture and manipulate photos were mainly driven by their wish to take and save photos of their children and grandchildren. Similarly, many participants were especially interested in learning to communicate via Skype so that they could maintain communication with their family members who live abroad. This seems to indicate the clear association between the older people's motivation and willingness to learn, and their willingness to strengthen the social ties with their family members.

It is worthy to note that the majority (89\%) of the older participants indicated their willingness to learn new digital skills. Out of those who indicated their willingness, 36\% indicated a strong desire to learn, and $53 \%$ indicated their willingness and acceptance to learn. Only 4\% of the participants showed their unwillingness to learn, and one participant refused to learn. The willingness of the majority to learn reflects their positive attitudes towards ICT technologies, and awareness of their significance in improving the quality of their lives. Nevertheless some challenges were reported by the students who participated in this study. Many of the students, for instance, indicated that forgetfulness was the main difficulty that the older participants faced. One of the students stated, "I had to repeat the steps and instructions around three times because the participant kept on forgetting them". Another student stated, "I had to repeat the steps several times so that the participant can memorise them." This forgetfulness, however, is not necessarily due to the influence of age only. It also seems to correlate with the level of education or educational attainment because most of the participants who forgot the steps did not have a university degree, and some did not finish school. Some studies suggest that age, education, and income are factors in an older person's interest in learning ICT skills (González, Ramírez, and Viadel 2015). The impact of educational attainment on later cognitive functioning has been established in previous studies, which found that older individuals who have a higher level of educational attainment perform better in cognitive functioning than those with less education (AIlaire and Whitfield 2004).

In order to reinforce and maximise the retention of the skills that the older participants learned, and evaluate their performance, the students asked the older participants to redo the procedures. The students' evaluation of older participants' performance was reported as follows: $31 \%$ of the students stated that the performance was excellent; $39 \%$ very good; $24 \%$ good; $5 \%$ weak; $1 \%$ bad. One of the students stated, "in the beginning, I thought that the older participant will forget the skills I taught him, but then I was surprised to see the participant learn quickly and perform all the steps easily later on".

Other challenges that were reported by the students included the following: "the participant was not able to see the small icons on Instagram. They were too small and not clear enough for him to click on them"; "My main challenge was the participant's slowness in typing due to unfamiliarity with the location of letters on the keyboard"; "The commands and settings were in English, and the participant only understands Arabic Language, so the main challenge was the participant's inability to understand the English icons and commands but I changed them into Arabic and things became much easier". Another challenge, which has been repetitively mentioned by a number of students is "forgetfulness" as one of them stated, "I had to repeat the steps several times so that the participant can memorise them". Another student stated, "the participant had difficulty in concentrating and remembering the steps", while a third student mentioned that he had to repeat one of the steps three times because the participant kept forgetting what each icon does. This challenge is understandable as the literature has shown that older adults tend to have lower memory and need more time to learn new skills (Tsai, Shillair, and Cotten 2017). These observations call for improvement in designing user-friendly technologies for older people, and also tailoring these technologies for Arab older people. Previ- 


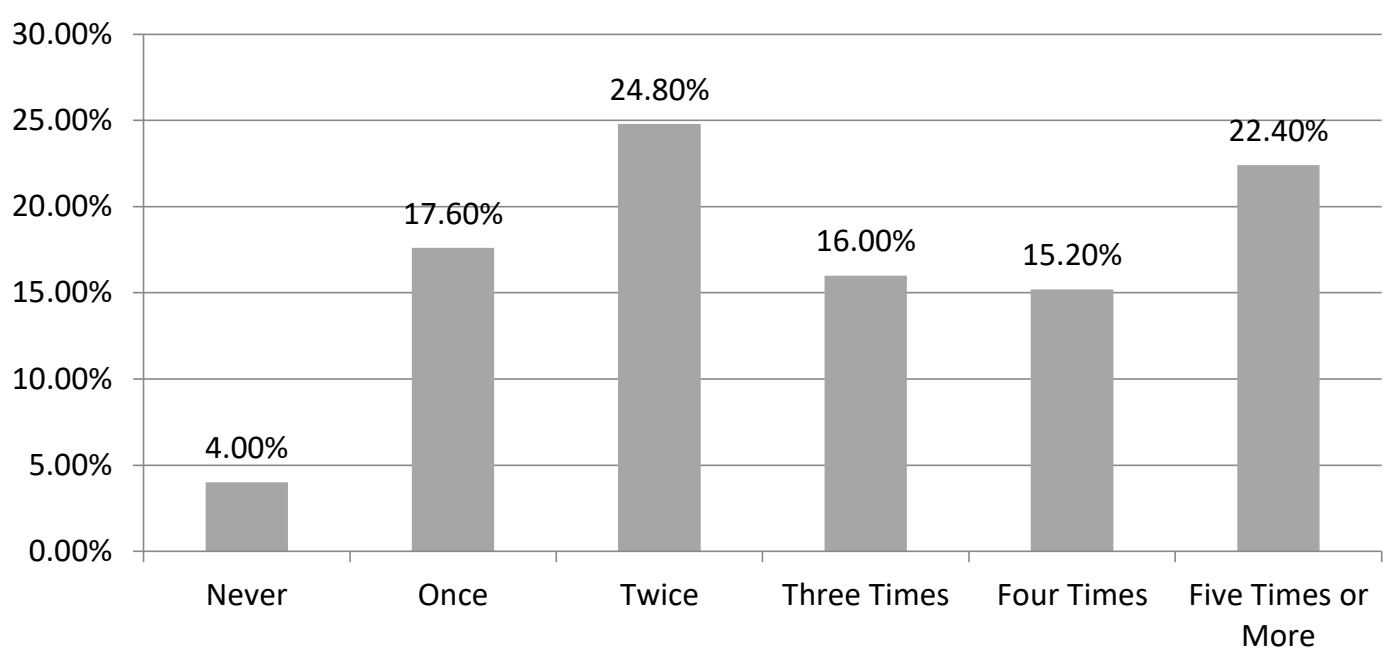

Figure 3. The number of times per month each of the students was asked by an older person for technical assistance.

ous studies indicated that there is a lack in the recognition of the specific design requirements by older people who have different abilities, and suggested that older people must be involved in decision-making in relation to the usability of operational features (Milligan and Passey 2011).

Despite these challenges, the desire to learn still seems to be strong among older people; the majority $(94 \%)$ stated that they were approached - before the project - by older family members, who asked them for help in learning various ICT skills. Furthermore, $76 \%$ of the students indicated that they already voluntarily taught older members of their families how to perform various techrelated tasks. Figure 3 shows how many times per month each of the students was asked by an older person for technical assistance or demonstration.

Thus, the older people's desire to learn seems to be reciprocal and on par with the youth's willingness to teach them. One of the students, for instance, stated, "I taught my 60 years old father how to save photos and videos from Snap Chat, but for your information, I have already started teaching him how to use this and other apps as well as and answering his technical-related enquiries about making online payments and accessing websites since long time ago." Another student stated, "I felt so happy when I saw my mother smile while I was teaching her. It is a good experience; I did it with my grandmother several times previously when I taught her how to use her mobile phone."

Several other students expressed their positive attitudes and feedback through the following statements:
I wish that all youngsters would spare some time to answer their parents' questions about technology; Teaching my grandmother how to use technology has never occurred to my mind as we all thought that she would not care about these things. She used to sit alone and watch T.V. for a long time, but she expressed her happiness when she started using different apps on her mobile after I taught her; This was a beautiful experience, which led me to laugh a lot with my mother and I was so happy to see her learn; This experience made me feel closer to my mother and allow us to talk to each other as we hardly have time to sit and chat; My father taught me everything when I was a child, and I am so happy now to take my turn in teaching him; This experience requires patience as older people need time to absorb technical skills, but it is gratifying, and it gave me the feeling of satisfaction and love to do good deeds for others; This was a beautiful initiative, which brings joy to older people's heart and reflects our attention and desire to assist older people in keeping up-to-date with our generation and all the progress.

The statistical results of our survey also reflect the students' desire to contribute to the enhancement of older people's digital literacy through expressing their wish to engage in such a project again. When asked if they would like to repeat it, $72 \%$ of the students chose 'yes', $27 \%$ chose 'possibly', and only $1 \%$ chose 'no'.

This mutual willingness and desire to engage in intergenerational digital learning must be further investigated from a psychological perspective as the above-mentioned results seem to reflect findings by previous studies which concluded that older people involved in learning technological skills 


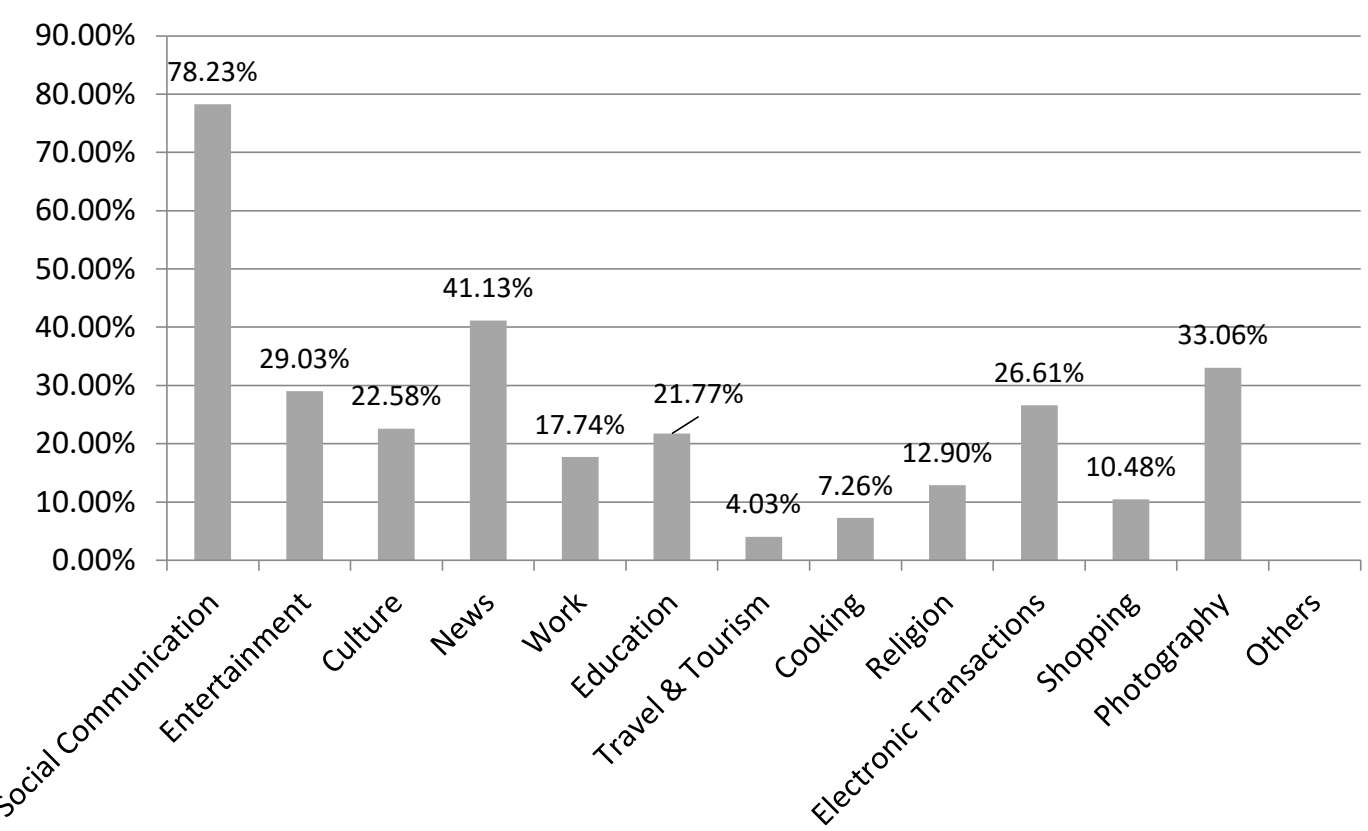

Figure 4. The categories of the skills that the older participants asked the young tutors to teach them.

"become more confident and have greater levels of self-esteem" (González, Ramírez and Viadel 2015, 5). The results in our research suggest that younger people involved in teaching digital literacy skills also seem to have greater levels of self-esteem due to their feelings of proficiency in technology, gratification, satisfaction, and gratitude.

In addition to self-esteem and perhaps other psychological motives, older people seem to have a number of practical reasons and objectives to learn technology. The results obtained from a previous study by González, Ramírez, and Viadel (2015) show that "the participants considered the learning, the communication, the entertainment, and the need to be up to date the main reasons to learn how to use the computer" (González, Ramírez and Viadel 2015). Communication and entertainment also seem to be some of the important objectives that the older participants in our project had. The students asked the older participants to request the tool, application, or skill that they would like to learn. The students were then asked to categorise the request or task into the categories shown in Figure 4. The results show that social communication was the most essential objective of the majority of the participants, followed by news, photo saving and editing, entertainment, e-services and transactions, culture and cultivation, and learning respectively. Other objectives such as work, religion, shopping, cooking, and travel and tourism seemed to be less important (Figure 4).

Most of the students performed the project with one of their parents, some of them chose to teach one of their grandparents, while others taught their aunts, uncles, and other relatives. Most of the older participants expressed their enthusiasm and willingness to learn in the beginning, but a small number of them felt tired or bored afterward. Six participants - four of them were males - expressed their unwillingness to learn. The education level of these six participants was below college level, which suggests a possible correlation between the educational level and willingness to learn. One of the students stated, "the participant was hesitant and expressed unwillingness to continue now and then". Another student stated, "In the beginning, he was very happy, but he was worried and anxious that he would forget what he learned". A third student remarked, "He accepted to learn in the beginning and was attentive, but he soon felt bored and asked me to continue by myself". Similarly, one of the students mentioned, "she was willing to learn but as soon as things got complicated, she would start withdrawing and complaining". The students, nonetheless, seemed unsurprised and ready to deal with such demotivation and unwillingness to learn. One of them stated, "It is not surprising to experience the unwillingness of older people to learn and keep pace with technology, because they lived in a period that was empty of all of this". Nevertheless, several students used effective tactics while attempting to overcome some of the challenges they faced during this experience. When asked about how they managed to facilitate the learning experience and overcome the challenges, many of them indicated that patience was a very important tactic. One of the 
students stated, "One must be very patient and not very serious while teaching older people". Another student stated, "I used simplified words and Arabic words to teach him easily and quick$l y^{\prime \prime}$, changing the language of the keyboard.

On the other hand, many of the students indicated positive outcomes and feedback as a result of their interaction with the older participants. One of the students stated, "It was a pleasure to benefit someone who I owe a lot, and what I taught him will not only benefit him but also the rest of the family". Another student indicated, "I was happy to teach her just like she taught me when I was a child". A third student stated, "I bought him a new mobile phone, and I was very happy to teach him until he becomes proficient in using $i t^{\prime \prime}$. A fourth student stated, "the happiness that my grandmother expressed was enough to make my day". Yet another student also stated, "my father taught me everything about life when I was a child, and I am so happy that this experience gave me the opportunity to feel that it is now my turn". These remarks suggest that sociocultural aspects may have an influence on the interaction between the young volunteers and the older participants. Respecting and honouring the older people in the Bahraini society, and in Islam in general, is the way Arabs are raised based on prophetic advice. This explains the pleasure and the feelings of gratitude which the students' expressed in the above-mentioned statements. In fact, one of the students expressed her pleasure and happiness to be involved in such an experience by stating, "The best of you who learn and teach what they have learned to others", which is derived from a Hadith by the Prophet Muhammad (PBUH). In addition to gratitude (Ehsan) and respect, patience (Sabr) or perseverance is also another characteristic that is mentioned in many verses in the Quran and Sunnah, which probably explains the reason that led several students to recommend the use of patience as a tactic to overcome the difficulties faced while teaching older people. The belief in these socio-cultural principles and religious values seemed to positively influence students' willingness to teach older people and to increase their motivation to continue teaching them, which made it very easy to find enthusiastic volunteers for such an intergenerational initiative in Bahrain. This motivation seemed to fuel the older participants' motivation and at the same time was being fuelled by it. One of the students stated, "seeing him happy made me happier". Some other similar statements by other students included: "I was happy because my grandmother was happy as I sat with her and helped her"; "I was happy as a result of seeing him happy to learn something he thought he would never learn before"; "It was rewarding to see how grateful he was to me for teaching him something new"; "I was happy to see how amazed my father was when he realized how easy it is to download a video and watch it offline later on"; "I felt happy when I saw my mother's smile while I taught her"; "My grandmother's happiness is part of my happiness"; "My grandfather's enthusiasm and motivation encouraged me to become even more motivated to teach him". Thus, the motivation was reciprocally rewarding and motivating. The older participants' motivation was influenced by their mere joy of getting the opportunity to interact and spend more time with the young students within a family informal context, which involved ordinary everyday chitchat and laughter now and then. This seemed to contribute to the impact of the intergenerational approach in strengthening social ties, which was evident in the following statements by some of the students: "the experience made me feel closer to my grandmother"; "I felt that there is a strong tie between us"; "It is a valuable experience which strengthens ties with others"; "This experience made me feel closer to my mother and chat more with her as I hardly have time to sit with her"; "In the beginning, she was worried as she thought that she would fail in using technology, but when I started explaining how to use the program she seemed very excited and was extremely happy beyond what anyone can imagine. She started hugging me and kissing me and even praying for me".

\section{Discussion}

Our main research question was: 'How intergenerational digital interaction may be implemented to bridge the digital divide and to provide opportunities for the youth and the older people to communicate and build a common ground of understanding?'

In order to provide a comprehensive answer to this research question, in this section, the results and outcomes from the previous section are discussed in relation to the research question. The findings suggest that to improve the digital literacy of older adults, social support can play a significant role (Tsai, Shillair, and Cotten 2017). They also suggest that the psychological, socio-cultural and emotional dimensions are as important as the physical aspects while analysing the challenges and motives of such an intergenerational approach.

The results also reflect the awareness of many older people in Bahrain of the importance and the advantages of digital literacy and indicate their willingness and readiness to acquire new technological skills. This willingness must be nurtured and supported through the establishment of a solid strategic plan for the digital inclusion of older people in Bahrain, especially with the recent plans to raise the retirement age in Bahrain to 65 and even 70 for some categories 
(Gulf Daily News, September 15, 2015). The President of the Supreme Council of Health, Shaikh Mohammed bin Abdulla Al Khalifa, stated that nowadays it is too early to retire at 60 , as the average life expectancy in Bahrain has reached 65 for men and 77 for women (Gulf Daily News, November 29, 2017). Thus, older citizens will be working longer than previously possible and they may leave the labour market than re-enter. With rising potentials of extended working life will come greater demand for empowering the older citizens with digital literacy skills to maintain their employability, boost their workforce productivity, and promote active aging by keeping them active and engaged in their workplaces and able to effectively contribute to Bahrain's prospering economy.

The attitudes, needs, objectives, anticipated benefits, experiences, interests, abilities, difficulties, challenges, and socio-technical contexts that were discussed in this section must be taken into account while designing suitable ICT training programs and initiatives that are tailored for older people.

In addition to these recommendations, the Grandparents and Grandchildren Project Report (2013) proposes a number of suggestions to take into consideration; older people's motivation to use technology and their awareness of its benefits and potentials to their general well-being must be promoted. Their training programs must be tailormade by asking them about the specific skills that they hope to acquire, and these skills should be directly applicable and useful in the trainee's everyday life. The training approach should provide the trainee with new opportunities to maintain contact with other people and to establish new contact with new people. Specific techniques must be employed to ensure that trainees continue to use the skills they learned, without losing the experience acquired from the tutor.

Moreover, while educating older people, intergenerational pedagogical approaches should utilise their accumulated life experience. Strategies should be sought and initiatives must be implemented to recognise, appreciate, utilise, exchange, and build on this experience for the benefit of both generations. The intergenerational approach has shown positive results for both the older participants and the students, including heightened learning of technological and interpersonal skills from interaction with another generation and improved attitude towards the other generation. The results in our research show that such an intergenerational approach in such a context where younger people are involved in teaching digital literacy skills to older people may lead to feelings of proficiency in technology, gratification, satisfaction, and gratitude. The experience increases cross-generational comfort levels, eliminating stereotypes that each generation may hold for the other. When taught by younger people, older people seem to become more motivated to learn computer skills and use technological devices. These results may have significant implications for the organisation of digital inclusion initiatives and training approaches, and for the social, digital, and economic prosperity in Bahrain.

Technological development in Bahrain does not call only for technological improvements through providing e-government services and Internet environments to allow Bahraini citizens to connect to the Internet and use their electronic devices, but also even more importantly for increasing motivation among the youth to digitally empower older people and encourage them to use technology. Therefore, there is an urgent demand to investigate, propose, and implement best ways to promote the digital inclusion of older people through designing tailored training programs and approaches that take into account the specific needs and preferences of older people; raising awareness about the benefits, possibilities, and potentials of using technology; promotion of ICT as a convenient means of obtaining information and facilitating various aspects in the lifestyle of older people like communication, news, entertainments, health, etc. It is also very important to demonstrate to the older people that on-line services like booking, shopping, banking, etc., which need sharing delicate personal data and credit card details, can be trusted and are not too complicated to use but, on the contrary, can make their lives much easier and many useful things more accessible.

Moreover, it may be beneficial for universities and schools to collaborate with the Ministry of Labour and Social Development to infuse intergenerational digital gratitude courses into academic programs. Educators must be encouraged to employ creative pedagogical strategies and create intergenerational digital learning opportunities for university and high school students and older people.

The implementation of the above-mentioned recommendations demands an effective digital transformation strategy in Bahrain that aims to empower and assist older people in various aspects of their lives. The establishment of a digital transformation strategy will prevent the digital exclusion of older people and exploit new digital opportunities for their e-inclusion.

Finally, the findings of this research must be considered under certain methodological limitations. The action-research project has been carried out using a questionnaire that was designed to be 
filled out by the students according to their observations and the feedback they get from the older participants, and not by the older participants themselves. Another limitation is that students administered the survey and carried out the project with their own older family members, allowing the experience and interaction to be influenced by their relationship, which might have affected how older people reported data. In order to draw more accurate conclusions, further research must be carried out to investigate the older participants' attitudes, interaction patterns, and preferences in relation to ICT usage. It is also important to investigate and measure the factors that affect their ICT usage, including social status, children, occupation, income, family relationships, education, gender, and language. These methodological limitations suggest that we should continue investigating the attitudes, challenges, patterns, and preferences of users with further studies before they can be considered fully ready for generalisation and application. Further research could lead to more conclusive findings of older people interests, needs, preferences, and patterns of using ICT, and the findings may subsequently be applied for guiding the design of ICT training programs and initiatives for older adults.

The practical implications and derived consequences of this research included a wider media outreach campaign aimed at promoting intergenerational communication and interaction by encouraging young people in Bahrain to contribute to the digital inclusion of older people by teaching them the various technical skills that may enhance their digital literacy. After undertaking this research and analysing its positive outcomes, the Art and Design students at the University of Bahrain visited five care houses and applied the approach with over 200 participants. This resulted in further theoretical implications and findings, which will be published in future research. Meanwhile, such campaigns and endeavours to assist elderly support must be launched in various regions especially in the Arab world. Governments must create programs that support the digital inclusion of older people through launching new intergenerational learning opportunities, and at the same time motivate older people to participate in digital learning activities by raising their awareness about potential benefits of using technology. Governments must also raise awareness about the needs of older people and emphasise their positive role in society in order to motivate young people to volunteer in various intergenerational activities. Governments may, thereafter, create a database of young volunteers, who are willing to teach older people and facilitate their digital inclusion and empowerment, and provide them with tech- niques and guidelines on delivering their digital skills to older people.

This intergenerational experience fostered a positive attitude among the mature and older participants with regard to their comfort in working with teens and the teens' respect for, ability to teach, and patience with older citizens. It provided an opportunity for the older people to feel less isolated, more confident, and learn new digital skills, and for the young to learn from the older people's experience. Overall, results suggest that intergenerational learning experiences benefited both groups in learning and skill development and led to a positive change in attitude towards the other generation.

The results of this research can be used to guide the development of strategies for improvement of the present situation in the use of technology by mature adults (aged 55-64) and older adults (aged 65+) as well as for the initiation and the promotion of exemplary practices in GCC countries and the Arab world. The outcomes from the Digital Gratitude Project should stimulate the care homes and the ministries of social development in Arab countries to apply this intergenerational approach in their programs. They should collaborate to act on the strategic insights and recommendations in this research in order to deliver national e-inclusion and digital literacy activities to benefit older adults, and the broader society as a whole. Moreover, universities should encourage their students to apply this approach with their older family members, and hence spur additional research that address further benefits and challenges of engaging with mature and older people.

\section{Conclusions}

The principal objective of this study was to explore how intergenerational digital interaction may be implemented in Bahrain to bridge the digital divide and to provide opportunities for the youth and older people to communicate and build a common ground of understanding. It also aimed to better understand old people's uses, perceptions, attitudes, needs, and challenges while using ICT, in addition to exploring the context in which technology adoption can become beneficial in strengthening familial relationships and bridging the Digital Divide between generations in Bahrain.

The study is an important contribution to the field of ICT usage by mature and older citizens in the Arab world, showing as it does that their attitudes may be positively affected by the implementation of an intergenerational approach for enhancing their digital literacy. The literature review has shown that mature and older adults 
who participate in intergenerational programs show a positive change in attitudes towards using technology. While learning ICT skills in an intergenerational context appeared to be a positive experience for both students and older adults, the findings proved that older people in Bahrain are not reluctant or unwilling to learn about technology, and are capable of learning various digital skills. The willingness of the majority of the participants to learn reflects their positive attitudes towards ICT technologies and awareness of their significance in improving the quality of their lives. The results also proved that learning digital skills through an intergenerational approach can stimulate self-confidence and augment self-esteem for older people, as well as a sense of satisfaction and gratitude for the youth, and therefore this approach can be implemented effectively in the promotion of active aging.

The results, however, indicated that forgetfulness was the main difficulty that the older participants faced. Other challenges included the inability to see the small icons, slowness in typing due to unfamiliarity with the location of letters on the keyboard, and inability to understand the English icons and commands. These challenges are understandable as the literature has shown that older people's ability to concentrate, remember, and solve new problems declines with age and significantly impacts their technology-adoption capabilities. These observations call for improvement in designing user-friendly technologies for older people, and also tailoring these technologies for Arab older people through involving them in decision-making in relation to the usability of operational features.

The study concludes that even older people with a low level of education and limited knowledge about technology may change their attitudes positively toward new technologies, as a way of communicating with others, saving memories through taking and saving photos, getting news and information, benefiting from the government e-services, and as a way of entertainment. In this way, the intergenerational approach presented in this paper can be considered appropriate for the elementary digital inclusion and the change of attitudes toward ICT of older people in Bahrain.

\section{Disclosure of interest}

The author reports no conflict of interest.

\section{References}

Akram, W. \& Kumar, R. (2017). A Study on Positive and Negative Effects of Social Media on Society. International Journal Of Computer Sciences And Engineering. 5(10), 347-354. https://doi.org/10.26438/ ijcse/v5i10.351354

Al-Ammary, J. (2010). Factors Affecting the Acceptance and Use of Computers and the Internet by Elderly People in the Kingdom of Bahrain. In Proceedings of the International Conference on Information Management and Evaluation, Cape Town, South Africa, 25-26 March 2010; Academic Publishing: Reading, UK.

Allaire, J. C., \& Whitfield, K. W. (2004). Relationships among education, age, and cognitive functioning in older African Americans: The impact of desegregation. Aging Neuropsychology and Cognition, 11(4),443-449. https://doi. org/10.1080/13825580490521511 Alolyan, A. A. (2015) The perceived impact of the internet on family and social relations in the Kingdom of Saudi Arabia. Doctoral thesis (PhD), Manchester Metropolitan University. Retrieved April 19, 2019 from https://e-space.mmu.ac.uk/id/eprint/608781

Alsridi, H. (2019) The Adoption and Use of Social Media and Its Impact on Mainstream Media in Bahrain. Journalism and Mass Communication, 9 (1), 13-25. https://doi/org/10.17265/2160-6579/2019.01.002

Alsswey, A., Umar, I. N., \& Al-Samarraie, H., (2018). Towards mobile design guidelines-based cultural values for elderly Arabic users. J. Fundam. Appl. Sci.,10(2S), 964-977. Antonio, A. \& Tuffley, D. (2018). Bridging the Age-Based Digital Divide;
Information and Technology Literacy: Concepts, Methodologies, Tools, and Applications. International Journal of Digital Literacy and Digital Competence (IJDLDC), 6(3), 1-15. https://doi/ org/10.4018/IJDLDC.2015070101

Arora, S. (2015). Social Networking-A Double-Edged Sword. International Journal of Advance Research In Science And Engineering (IJARSE), 4 (1).

Atkinson, K., Barnes, J., Albee, J., Anttila, P., Haataja, J., Nanavati, K., \& Steelman, K, Wallace, C. (2016). Breaking Barriers to Digital Literacy: An Intergenerational Social-Cognitive Approach. ASSETS '16 Proceedings of the 18th International ACM SIGACCESS Conference on Computers and Accessibility pp. 239-244. https://doi/ org/10.1145/2982142.2982183

Bahrain E-Government Portal https://bahrain.bh/wps/ portal/!ut/p/a1/jzbnc4iweiz_iweu7jk0kfywruutdj1slotigbodhsqmuphnf_vuv8redud5zt9debcbkjldrixnrhdjfugfw059zbaxyrwdwpchl2-b7_qww2ghxh8asififtz8hy6ecloxn4_eg1uzhw7wperujz7cz9cxokn7-jek_7s_kav8gtjdlq84avdinodboeygvk7t409jxqtuviaquzavrmyfqhtntvpwzwya2latqbrwutrxemummyhxrezxduqxmjtbmiz2s-_hfodyphj8ahwx7-g!/dl5/d5/l2dbisevz0fbis9nqseh/ Bolin, G., \& Skogerbø, E. (2013). Age, generation and the media. Northern Lights, 11(1), 3-14. https://doi/ org/10.1386/nl.11.3_2

Condotta, H. (2018). Social media: A double-edged sword?. British Dental Journal, 224, 701. https://doi. org/10.1038/sj.bdj.2018.382

Czaja, S. \& Lee, C. C. (2007). The impact of aging on access to technology. Universal Access in the Information Society (UAIS), 5 (4), 341-349. https://doi/ org/10.1007/s10209-006-0060-x

Elmasry, T., Benni, E., Patel, J. \& aus dem Moore, J. P. 
(2016). Digital Middle East: Transforming the region into a leading digital economy, McKinsey \& Company, https://www.mckinsey.com/ /media/ mckinsey/global\%20themes/middle\%20east $\% 20$ and $\% 20$ africa/digital\%20middle $\% 20$ east $\% 20$ transforming $\% 20$ the $\% 20$ region $\% 20$ into $\% 20 a \% 20$ leading\%20digital\%20economy/digital-middleeast-fin al-updated.ashx

González, A, Ramírez, M. P., \& Viadel, V. (2015). ICT Learning by Older Adults and Their Attitudes toward Computer Use: Current Gerontology and Geriatrics Research, 2015(5), 849308, https://doi. org/10.1155/2015/849308. Grandparents \& Grandchildren Project (2013). "Digital Literacy Training for Adults: Initiatives, Actors, Strategies - Guidelines concerning adult literacy teaching strategies for people aged over 55", research report downloaded from http://www.geengee.eu/geengee/ geengee-docs/contenuti/comune/G\&G\%20Research\%20Report.pdf Hoff, A. (2007). Intergenerational learning as an adaptation strategy in ageing knowledge Societies. European Commission (Ed.), Education, Employment, Europe, National Contact Point for Research Programs of the European Union, Warsaw, pp. 126-129.

International Center for Research on Women (2003). The Intergenerational Approach to Development: Bridging the Generation Gap. Retrieved August 20, 2019 from https://www.icrw.org/wp-content/uploads/2016/10/The-Intergenerational-Approach-toDevelopment-Bridging-the-Generation-Gap.pdf

Khawaji, M. A. (2017). "Overcoming challenges in smart phone use among older adults in Saudi Arabia" Graduate Theses and Dissertations. 16155. https://lib.dr.iastate.edu/etd/16155

Lindsay, S., Smith, S. \& Bellaby, P. (2007). The Impact of ICT on Family: Views from an older generation: Family and Communication Technology Workshop. https://www.northumbria.ac.uk/ static/5007/2008pdf/fact_impactfamily.pdf LIST, (2013). Leveraging the Digital \& ICT Competences of senior women to extenuate the knowledge divide. Retrieved August 6, 2018 from https://www. zsi.at/object/project/2761/attach/LIST_Methodological_Guide.pdf

Livingstone, S. \& Haddon, L. (2009). EU Kids Online: Final Report. EC Safer Internet Plus Programme Deliverable D 6.5, London: London School of Economics and Political Science.

Madianou, M., \& Miller, D. (2013). Polymedia: Towards a new theory of digital media in interpersonal communication. International Journal of Cultural Studies, 16 (2), 169-187. https://doi/ org/10.1177/1367877912452486

Mesch, G. (2006). Family characteristics and intergenerational conflicts over the internet: Information, Communication \& Society 9(4): 473-495.

Neves, B. \& Vetere, F. (2019). (Eds.) Ageing and Digital Technology: Designing and Evaluating Emerging Technologies for Older Adults. Springer.

Niehaves, B., \& Plattfaut, R. (2013). Internet adoption by the elderly: employing IS technology acceptance theories for understanding the age-related digital divide, European Journal of Information Systems 23
(6): $708-726$

Kolodinsky, J., Cranwell, M., \& Rowe, E. (2002). Bridging the Generation Gap across the Digital Divide: Teens Teaching Internet Skills to Senior Citizens. Journal of Extension, 40(3). Retrieved July 4, 2018 from https://www.learntechlib.org/p/94022/

Lanigan, J. D. (2009). Computers in the family context: Perceived impact on family time and relationships. Computers in Human Behavior 28(2), 434-443. McCann, J., \& Bryson, D. (2015). Textile-led Design for the Active-Ageing Population. Cambridge: Woodhead Publishing.

Milligan, C \& Passey, D. (2011). Ageing and the use of the internet - current engagement and future needs: state-of-the-art report. Nominet Trust. Moawad, G. \& Ebrahem, S. (2016). The Relationship between use of Technology and Parent-Adolescents Social Relationship. 7th ed. Journal of Education and Practice, pp.168 - 176. Available at: https://files. eric.ed.gov/fulltext/EJ1103022.pdf [Accessed 4 July 2018]. Neves, B. B., \& Amaro, F. (2012). Too old for technology? How the elderly of Lisbon use and perceive ICT. The Journal of Community Informatics $8(1), 1-11$.

Patrício, M. R., \& Osório, A. (2016). Intergenerational Learning with ICT: A Case Study. Studia Paedagogica, 21(2), 83-99. https://doi.org/10.5817/SP2016-2-6

Rønning, W. M. \& Sølvberg, A. M. (2017). Older Adults: Coping with the Digital Everyday Life. Seminar. Net, 13(2). Retrieved September 4, 2018 from https://journals.hioa.no/index.php/seminar/article/ view/2307 Roupa, Z., Nikas, M., Gerasimou, E., Zafeiri, V., Giasyrani, L., Kazitori, E. \& Sotiropoulou, P. (2010). The use of technology by the elderly. Health Science Journal 42, 118-126.

Shaw, S.E. \& Bailey, J. (2009). Discourse analysis: what is it and why is it relevant to family practice? Fam Pract. 26(5), 413-419. https://doi/org/10.1093/fampra/cmp038

Siddiqui, S. \& Singh, T. (2016) Social Media its Impact with Positive and Negative Aspects. IJCATR, 5 (2), 71 - 75. Subramanian, Kalpathy. (2017). Influence of Social Media in Interpersonal Communication. International Journal Of Scientific Progress And Research (ljspr) 109. 70-75. Taipale, S. (2019). Technologies of Re-familization. In: Intergenerational Connections in Digital Families. Springer, Cham. https://doi.org/10.1007/978-3-030-11947-8_9

The National Strategic Plan for the Elderly in Bahrain. (2012). http://www.mlsd.gov.bh/sites/default/files/ img/files/eldarlystra.pdf Tsai, H. S., Shillair, R. \& Cotten, S. R. (2017). Social support and 'playing around': An examination of how older adults acquire digital literacy with tablet computers. Journal of Applied Gerontology, 36(1): 29-55. https://doi/ org/10.1177/0733464815609440

UNECE (2019). Advancing digital and social inclusion through intergenerational learning and empowerment. Retrieved August 20, 2019 from http://www. unece.org/info/media/news/population/2019/advancing-digital-and-social-inclusion-through-intergenerational-learning-and-empowerment/doc.html

UNPAN (2016). UN e-Government Survey 2016. EGovernment in Support of Sustainable Develop- 


\section{Empowering mature and older people's usage of digital media}

ment. New York: UNPAN. Retrieved August 02, 2018 from http://workspace.unpan.org/sites/Internet/Documents/UNPAN96407.pdf

World Economic Forum (2016). "Digital Media and Society Implications in a Hyperconnected Era". World Economic Forum Shaping the Future Implications of Digital Media for Society project report.
http://www3.weforum.org/docs/WEFUSA_DigitalMediaAndSociety_Report2016.pdf

Ye, L. and Yang, H. (2020). From Digital Divide to Social Inclusion: A Tale of Mobile Platform Empowerment in Rural Areas. Sustainability, 12(6), 2424. https:// doi.org/10.3390/su12062424 